\title{
Directions for Health Education: \\ New Spokes in the Wheel...Or a New Wheel
}

\author{
Beverly G. Ware, Dr.P.H.*
}

University of Michigan

\begin{abstract}
This paper, presented as a Presidential Address at the 25th Annual Meeting of the Society for Public Health Education, examines the current state of SOPHE and the practice of health education. It begins with a review of current issues impacting on SOPHE and health education, and then assesses the current directions both are pursuing. Needs to be addressed and implications for the future are suggested.
\end{abstract}

We are now in the center of a gathering storm over health care when economic factors are overriding and when we have seen that more dollars and more people will not a solution make. Just recently, the U.S. Office of Education reported results from a study conducted by the University of Texas indicating that over 20 percent of the U.S. population is functionally incompetent to maintain good health.s Think of the money that has gone into our education systems! And think also of all our efforts to help people help themselves!

It is clearly acknowledged by most of us that at the present time health education is back on center stage as a necessary component of any health care delivery system. Articles appearing recently from such widely diverse sources as The Public Interest ${ }^{1}$ and New England Journal of Medicine ${ }^{3}$ have paid special attention to health education as essential to both health and to current and future delivery systems for health care.

Last summer legislation specific to health education had some success in Congress. There is a mandate for health education in the new "National Health Planning and Resource Development Act of 1974" and there is now a focus for health education in HEW, the Bureau of Health Education in Atlanta. A new National Center for Health Education has been established.

\footnotetext{
* Coordinator, Cardiovascular Risk Intervention Program, Ford Motor Company, World Headquarters, Dearborn, Michigan 48121 and formerly Assistant Professor of Health Education, Department of Health Behavior and Health Education, School of Public Health, The University of Michigan
} 
Increasingly, health education has become or is being considered a funded benefit by thind-party payors in health care delivery. Patient education is receiving considerable attention in hospitals and health maintenance organizations all over the country, and new programs are emerging faster than one can keep up with the developments. Grants allocating large sums of money to develop community education programs have been awarded by the National Cancer Institute and the National Heart and Lung Institute. The growing attention to education in health can be taken to mean that at long last the importance as well as the potential of health education can be realized.

More attention to the educational component in health means that there has been more attention as well to the professional practice of health education. SOPHE especially has taken on this responsibility. Increasingly, the organization has been actively concerned with all of the events mentioned, both to emphasize the importance of professionally trained health educators within these activities and to support, to reinforce, to legitimize, to criticize, and to sanction proposed changes and developments concerning the practice of health education.

But in which directions are SOPHE and health education heading? To address this question, return for a moment to the title of this paper. If we consider SOPHE to be the hub, and the rim of the wheel to be health education, then the spokes are the components tying the two together. Something is wrong with the old wheel. The spokes, those components between health education and SOPHE, are no longer fitting and the rim is pulled and pushed out of shape.

The components are becoming larger and are including many areas. For example, interest in health education programs as part of any health care delivery has been rapidly increasing. Concerns with the rising costs of providing medical care, the proper utilization of services by those who use them, problems in adherence to medical regimens, the need to have understanding as part of informed consent, the need to help people help themselves, the rise of malpractice suits - these are some of the forces influencing the development of consumer health education.

Where is the health educator in all these areas and what are the health educators doing? Many are there, and the wide variety of what is being done by professionally trained health educators is impressive. However, the variety is so great that the image of a professionally trained health educator is not clear. How can it be clear when the activities undertaken include educational program planning and training with multidisciplinary teams of health professionals on the one hand to individual and group counselling of patients on the other hand? There is little agreement on what is the role and function of a 
health educator in health care delivery. All that has been available for the most part are documentations of successul practice.

Another component that has emerged with increasingly potential significance is legislation. Measures specifically dealing with health education have been introduced in Congress within the past year. Some have addressed strengthening a federal focus for health education within the Department of Health, Education and Welfare. Others are designed to encourage, through financial aid, innovative approaches to consumer health information programs by advertising and insurance companies. The thrust of activities with respect to legislation has caused SOPHE, as an organization keenly interested in the development of health education, to become more responsive to legislative happenings, and to direct our efforts toward influencing political processes, especially on the national level.

Concurrently, many members of the profession of health education, including SOPHE members, have become more aware and concerned with political issues, and often have become involved in legislative matters. But a polarization has also taken place between those who think we have not moved fast enough to respond, and in fact have challenged the reactive stance of SOPHE, and those who would have us stay on the periphery of political processes, the activists versus the humanists, perhaps. The activists in health education have pushed hard for more direct involvement and more activity, while the humanists have emphasized as their primary concern the tasks of helping people rather than becoming involved with political issues. Such clashes have created sharp divisions in the membership with respect to the means utilized to achieve goals.

Yet another component in which SOPHE has always spent much time and effort in providing leadership is the area of professional preparation and practice. The rapid growth, especially over the past five to ten years, of additional full time health education practitioners, namely health education aides and the bachelor's level community health educator, has had and will continue to have an influence both on health education and the professional practice of health education. We have not yet realistically dealt with the implications of this growth for both SOPHE and the professional practice of health education.

The monumental task of developing guidelines for bachelor's programs is an example of a SOPHE sponsored and funded undertaking directed toward providing a document which could be utilized by programs now preparing bachelor's level community health educators. This document will for the first time suggest both curriculum and competencies for this practitioner.

Other areas of concern are with the current accreditation of master's programs and with developing a revised set of standards for practice. Issues arising from our efforts in the professional practice of health 
education have convinced the SOPHE Board of the need to go yet much further; to examine the possibility of licensure or certification for health educators.

Our organization has been concerned also with the external views that exist of SOPHE and of health educators. Many of our fellow health professionals never have heard of either, while being aware of health education. More dismaying yet, if they do know about is, they sure don't think much of us or what we can do. Many of you currently in professional practice have achieved degrees of status for yourselves that may be quite independent of being a health educator or a member of SOPHE.

What have we done to enhance our image as professionals? There have been few contributions made to the body of written knowledge by practitioners. There is little solid evidence from health educators that health education works. There is scant display of scientific rigor in what we do in the practice of health education. There are few who consider involvement with and contribution toward the growth and development of the profession as important to their own personal professional development. There are so few who consider professional preparation as only the first step in professional development. Too little effort is placed on determining what we produce and how effective we are. ${ }^{6}$ We go to great efforts to find ways to influence consumers of services to be more responsible, but our own responsibilities to the professional practice of health education are quite narrowly defined.

I would be remiss if I did not say that those professional health educators who join SOPHE do so primarily for professional identification and for the continuing education such membership provides. But what of those who don't join, or who fail to renew their membership or become inactive? What is the effect on our image when so many of us are no longer called health educator in our job title?

I have raised these issues to indicate the forces that are affecting the balance between the rim of the wheel and the hub, between the field of health education and SOPHE. How can we create a wheel that is in shape, that rolls smoothly?

First, the future of SOPHE, the hub, rests squarely with the future of health education practice by all health professionals as well as on the future of the professional practice of the health educator. Both must be addressed, and in balance.

We must be able to address realistically the growing interest in and practice of health education by other health professionals as well as those professionally trained in other areas who look to using their skills within health systems. Five years ago SOPHE changed its name to the Society for Public Health Education and expanded its membership potential. Yet there still exists some of the old "elitist" 
notion of the Society. Are we yet secure enough to broaden ourselves in the future? While we seek to generate new members from a wide variety of sources, what are we going to do with these members? How can they be part of us and not be lost after a year? There is the further challenge of recruiting into membership those professionally trained health educators who move into new areas not directly as health educators, but who, nevertheless, still utilize health education practice.

The professional practice of the health educator will increasingly become more differentiated. The efforts of SOPHE with respect to this area are revealing unanticipated consequences. It is already apparent that the baccalaureate level trained health educator is and will continue to be the entry level practitioner. Competencies and skills expected from this level were just a few years ago the contents of curriculum for the master's degree. The need to examine competencies and training for this latter degree was recognized and SOPHE responded to this challenge, but the task is an overwhelming one, and may take years to accomplish.

Second, neither SOPHE nor the professional health educator is going to have much real impact on the forces affecting health education in health care delivery. We are caught up by these forces. The resurgence of interest in health education has occurred, not because of our efforts, but almost in spite of them. Our task must be to learn to anticipate change, to work for the changes we know are needed, as well as to ride with the waves of change.

As an organization we have been most successful in riding with the waves of change, and somewhat less successful in securing the changes we know are needed. For example, in both the President's Committee and in the recent efforts with respect to national legislation for health education, the Executive Committee and Board of Trusiees of SOPHE kept the membership informed of the changes to expect as well as those already in progress. Members were encouraged to engage in activities to support the changes. Individual SOPHE members were able to anticipate directions and potential for change, and to even influence the change, yet SOPHE itself had no power or legitimacy to effect any change on its own.

From these experiences come the realization that there is a need to more systematically link with those who do anticipate change by virtue of their position or skills, and to plan ahead more realistically.

Third, whatever is wrong with SOPHE as an organization is wrong with the professional practice of health education itself. If SOPHE is trying to be all things to all members, it can just as easily be said that health educators are at the same time conducting a very wide range of professional activities in a variety of settings. They are trying to be all things in health education and perhaps that is the last thing they 
should be doing.

Perhaps what we should be doing is putting all of our energies and abilities into improving the practice of health education by all health professionals. We can do this by concentrating on planning and evaluating educational programs and activities, on training and on consulting, on continuing our quest for excellence in professional practice. It is not enough to relate to consumers of health services; we must also relate to our health colleagues, even to the extent of concentrating our efforts on developing education skills among those who deliver health services and becoming system change practitioners.

We must learn to relate better to each other. Linkages to other professional health education organizations must continue, with SOPHE taking the leadership, if necessary. Increasingly other professions who have an interest in and who are active in health education must become our partners for health education.

Is there to be a redefinition of the professional practice of health education? Certainly for the master's level practitioner there must be. While there may be little disagreement with the many definitions of health education, there is much to be unhappy with in the definition of a professionally trained health educator. Performance expectations are vague. They do not clearly define in any detail competencies and skills. It is not so much that professionally trained health educators do many things under many titles that is of concern here, but rather that we at least agree for sure that there truly is a common core from which we start.

Moreover, the professional practice of health education is both an art and a science. Can we easily categorize the "art" of helping, or the - limits of "influencing" or what is "developing awareness," or even "collaboration?" Where then does our uniqueness originate - from our science of practice or from our art of practice? Or from our professional preparation? These questions must be answered by us clearly. It will not be easily done. We will have conflicts and problems, but we can do it.

The key to the future of both SOPHE and the professional practice of health education is change. Efforts must be directed toward determining what is amenable to change, what is the potential for change, and what will be effective in directing change. Lippitt's ${ }^{2}$ jargon translates into our being able to decide the directions that will be most effective to take, temper these decisions with reality, and to hold ourselves accountable for our actions. What SOPHE and health education has to look forward to is still more hard work over the years ahead. SOPHE must seize or create any opportunity to influence and become a part of the future practice of health education. Therein is its tomorrow. 


\section{REFERENCES}

1. Kass LR: The pursuit of health. Public Interest 40:11-44, 1975.

2. Lippitt R, Watson J, Westley B: The Dynamics of Planned Change. New York, Harcourt, Brace and Company, 1958, pp 145-162.

3. Modern life is too much for 23 million Americans. U.S. News and World Rep, November $10,1975, \mathrm{p} 84$.

4. Preventive medicine: Legislation calls for health education. Science 189:1071-1072, 1975.

5. Rabkin MT: The needs of patients. New Engl J Med 288:1019-1020, 1973.

6. Richards ND: Methods and effectiveness of health education: The past, present and future of social science involvement. Soc Sci Med 9:141-156, 1975. 